\title{
Will mixing rule or chemical reactions dominate the ash behavior of biomass mixtures in combustion processes on laboratory and pilot scales?
}

\author{
Emile ATALLAH ${ }^{1}$, Françoise DEFOORT ${ }^{1}$, Matthieu CAMPARGUE ${ }^{2}$, Alexander PISCH ${ }^{3}$, Capucine \\ DUPONT ${ }^{4}$
}

\footnotetext{
1 Université Grenoble Alpes, Commissariat à l'Energie Atomique et aux Energies Alternatives (CEA), Laboratoire d'Innovation pour les Technologies des Energies nouvelles et les Nanomatériaux (LITEN), DTCH, F-38000 Grenoble, France 2 RAGT Energie, F-81000 Albi, France

${ }^{3}$ Université Grenoble Alpes, CNRS, Grenoble INP, SIMaP, 38000 Grenoble, France

${ }^{4}$ IHE Delft Institute for Water Education, Department of Water Supply Sanitation and Environmental Engineering, Delft, the Netherlands
}

\section{Abstract}

Mixing biomasses has a good potential to solve operational problems in thermochemical valorization processes related to ash behavior. Chemical reactions within the ash of the blend, and not only a mixing effect without reaction, need to take place to form new solid phases in the mixture at the expense of getting rid of the problematic liquid one to decrease the slagging tendency. The present work focuses on assessing the presence of a chemical reaction in comparison with a simple mixing effect within the ash of mixtures of wheat straw - oak bark biomass and ash in two laboratory setups and in a fixed and in a moving bed pilot combustion reactors. The operating conditions were varied to study their effects on the reactivity of the ash within the mixtures. This aimed to optimize the ash reactivity and to assess the capabilities of the laboratory test to predict the ash behavior in pilot-scale reactors.

Mixing without reaction effect was more evident when mixtures of biomass were used on both laboratory and pilot scales. In this case, the simple mixing rule was able to simulate the general ash behavior of biomass mixture to a certain extent that exact prediction was always limited by the presence of certain chemical reactions. However, chemical reactions effect was dominant when mixtures of ash of biomass were applied as feedstock. Solid crystalline phases $\mathrm{K}_{2} \mathrm{Ca}_{2} \mathrm{Si}_{2} \mathrm{O}_{7}$ and $\mathrm{K}_{2} \mathrm{Ca}_{6} \mathrm{Si}_{4} \mathrm{O}_{15}$ were the direct end products of these chemical reactions. Their relative proportion was inversely proportional to the problematic amorphous phase in the final ash. Hence, optimizing the blend proportion to increase their concentrations has the potential to solve slagging problematic. These two compounds were mostly stable at $1000^{\circ} \mathrm{C}$, at which equilibrium was reached after $6 \mathrm{~h}$. However, they existed at a lower proportion at $850^{\circ} \mathrm{C}$ and disappeared at $1200^{\circ} \mathrm{C}$. The developed laboratory pellet test was also able to predict very efficiently the pilot ash behavior of both individual biomasses and their mixture in terms of crystalline and amorphous composition and proportion along with agglomeration distribution.

Keywords: Biomass mixing, biomass ash, prediction approach, pilot plant scale, chemical reaction, operating conditions. 
2 The worldwide energy demand is continuously increasing with the population and economic

\section{Introduction} growth, and is projected to reach around 250000 TWh in 2040 [1]. Biomass, when used as fuel in thermal conversion processes such as combustion or gasification, has the potential to satisfy more than $60 \%$ of this increasing energy demand [2]. However, these fuels are characterized by various ash yields $[3,4]$ and a wide range of ash compositions that induces various problems when applied in thermochemical conversion processes [5].

Many agricultural residues, such as wheat straw, are characterized by high alkali-silicate contents that lower the melting point of the resulting ash and lead to the occurrence of a liquid phase, even at relatively low temperatures (i.e. $800^{\circ} \mathrm{C}$ ) [6]. Hence, they can form agglomerates in fluidized bed reactor (FBR), i.e. ash in the liquid phase that sticks or reacts with the bed materials, or induce sintering effects in furnaces, i.e. ash in the liquid phase that sticks to the bottom of the reactor or its walls. This can lead to blocking, fouling, clogging the reactor along with instrument shutdown, poor degradation by combustion reaction, and increased operational costs [7]; ash in the solid phase is preferred in this case. On the contrary to the cases of the furnace and the fluidized bed, ash in the liquid phase is highly needed in an entrained flow reactor (EFR) to control the temperature and flow of ash on the walls $[8,9]$.

In contrast with agricultural residues, ash of wooden biomass is rich in calcium-silicates that produce ash in the solid phase, even at high temperatures (i.e. $1300^{\circ} \mathrm{C}$ ), which makes them good candidates for furnace and FBR but not for EFR. Consequently, using one type of biomass can yield ash in either the solid or the liquid phases, or even sometimes produce a mixture of liquid-solid phases; hence posing several limitations on the applied process.

Additives were widely used to decrease agglomeration and sintering levels, but each has its own problem [10-13]. Their cost is usually high and their application depends on the 
feedstock $[10,14]$. Aluminosilicates based additives were able to effectively reduce the fine particulate matter emissions, but they increased the gaseous emissions of $\mathrm{HCl}$ and $\mathrm{SO}_{\mathrm{x}}$ [15]. Kaolin also proved to be a good additive especially in decreasing the slag formation; but they tend to increase $\mathrm{HCl}, \mathrm{SO}_{\mathrm{x}}$, and $\mathrm{NO}_{\mathrm{x}}$ emissions $[10,16]$. This was the similar case with dolomite additives [17]. Phosphorous based additives, such as $\mathrm{NH}_{4} \mathrm{H}_{2} \mathrm{PO}_{4}$ in the work of Wang et al. [18], successfully decreased slag formation, but at the same decreased the integrated combustion characteristic index and their efficiency depended on the inorganic composition of the fuel that they were added to. On the other hand, biomass mixing proved to be a more suitable solution than additives to fight slagging and agglomeration in terms of cost and effectiveness [19] and triggered the interest of many researchers during the last thirty years [6,20-24]. Mixing biomasses with different ash contents and compositions at various ratios modifies the chemical composition and physical properties of the feedstock. Then upon heating, chemical reactions within the ash can take place to form new solid phases in the mixture and reduces therefore the percentage of the liquid phase [2-3]. However, mixing without interaction can also take place, hindering the chemical reactions and enhancing the problematic phase. The chemical reactions within the ash of the biomass mixture, which highly depend on operating conditions, were the interest of several researchers in the field $[6,21,25-27]$, especially in laboratory-scale experiments. Some of them suggested various reaction pathways that might take place between the inorganic elements of the ash of biomass $[6,28,29]$.

Biomass mixing can affect ash behavior not only in laboratory furnaces but also in pilot reactors. For instance, Salour et al. [30] cofired wood and straw in a more than $50 \%$ wood fraction mixture in a pilot fluidized bed combustor at $800^{\circ} \mathrm{C}$. They have found that bed agglomeration was intensified when straw reached $50 \mathrm{wt} . \%$ in the wood-straw mixture due to an increasing interaction within the ash of the two biomasses as straw fraction increased in the 
blend [30]. Nordgren et al. [31] co-fired wheat straw and softwood bark in a $150 \mathrm{~kW}$ pulverized fuel-fired burner and found that the tendency for both fouling and slagging was reduced when mixtures were applied instead of single biomasses. They referred to both a dilution (i.e. mixing without chemical interaction) and interaction effect taking place in the straw-bark mixtures [31]. In their study, Zeng et al. [21] used various binary mixtures of wood, wheat straw, and miscanthus in a small scale combustion appliance with a nominal heat capacity of $30 \mathrm{~kW}$. They found that adding wood to straw significantly increased the bed and sintering temperatures, especially in the mixtures with more than $70 \mathrm{wt} . \%$ wood [21].

Instead of trial-and-error or systematic proportional mixing from 0 to 100 , a prediction tool can be developed to adapt the type and composition of the biomass mixture to the applied process. Empirically derived indices are widely used to predict the ash behavior of coal but showed significant limitations in the case of biomass [24,32-34]. This might be due to the abundant iron and alumina-silicate ash contents in coal compared to the high calcium and alkali-silicates in biomass [24,32]. Several researchers proposed the use of a thermodynamic tool, i.e. the CaO$\mathrm{K}_{2} \mathrm{O}-\mathrm{SiO}_{2}$ ternary phase diagram to predict ash behavior, such as Rebbling et al. [28], Zeng et al. [21], Defoort et al. [27], and Ohman et al. [7]. Despite the relative success of such a prediction tool, the same authors concluded that the thermodynamic database needs to be revised since some crystalline phases appeared experimentally but were absent in the database [27], and the calculated liquidus line differed from the experimental results [21,28]. The main drawback of the thermodynamic prediction tool is that it provides results at equilibrium, which might or might not be the case in real processes, especially on an industrial scale. Hence, laboratory tests are still a mandatory step to evaluate the ash behavior in a pilot plant.

Various laboratory ash behavior prediction tests were used to investigate the behavior of biomass mixtures, such as the Bioslag test [24], thermogravimetric analysis-differential thermal analysis (TGA-DTA) [35], rapid qualitative test [36], and standard ashing test [35]. However, 
these tests are usually time-consuming, were rarely compared to results obtained on a pilot scale, and depend on the feedstock, reactor type, and operating conditions [24,35]. For instance, Gilbe et al. [37] compared the slagging tendencies predicted by the ash fusion test (SS ISO540), TGA/DTA, thermodynamic phase diagrams, and a laboratory scale-sintering test with those in a $20 \mathrm{~kW}$ pilot reactor. They used 12 different single biomasses, including wheat straw and various barks, and they found that the four laboratory tests failed to quantitatively predict the slagging behavior in the pilot, leading to different experimental results when compared with the predicted values [37]. However, these methods were able to predict the same fuel-specific slagging qualitative trends as the corresponding combustion behavior [37]. Authors mentioned that further improvements need to be done on the tests, especially the TGA/DTA and the SS ISO 540 tests [37].

In this work, single bark, single straw and their 50-50 mixture in the form of biomass and ash were used in two different laboratory combustion set-ups and in fixed and moving bed combustion pilot reactors. This work applied full crystalline phase quantification (including the amorphous phase), instead of the limited semi-quantification in the previous work of Defoort et al. [27] for example. The first and main objective was to evaluate the presence of chemical reactions in contrast with mixing without interaction within the ash of the mixtures. The second objective was to study the effect of temperature, residence time, and cooling rate on the ash reactivity of the mixtures on laboratory scale. This helped find the optimum equilibrium condition at which the ash problematics were at minimum, in the case of straw-bark mixture. In addition, by comparing the experimental results of the laboratory tests under the various operating conditions against those in the pilot scale combustion reactors, the capabilities of the laboratory tests to predict the ash behavior of biomass mixtures in pilot reactors were assessed. To our knowledge, this type of assessment was never done, especially using biomass mixtures, in any of the aforementioned laboratory prediction tests. 


\section{Materials and methods}

102 Defoort et al. [27] found that 50-50 wt.\% biomass bark-straw mixture (called MP2b) lies in the

103 middle of the solid section in the ternary phase diagram $\mathrm{CaO}-\mathrm{K}_{2} \mathrm{O}-\mathrm{SiO}_{2}$, and hence it will be

104 applied in this work. The elemental composition of every single biomass, i.e. oak bark, wheat

105 straw, and their 50-50 wt.\% biomass bark-straw mixture (i.e. MP2b), was measured by an

106 Elementar Vario EL cube CHNS Analyzer along with an inductively coupled plasma atomic

107 emission spectroscopy (ICP-AES) and were the same as the ones presented in related previous

108 work [27]. The measured elemental composition of the biomasses and their mixture is shown

109 in Table 1.

110 Bark weight fraction in the ash bark-straw mixture $(\beta)$ can be calculated from bark weight

111 fraction in the biomass bark-straw mixture $(\alpha)$, taking into account the ash yield of the parent

112 fuels (noted $A_{1}$ for bark and $A_{2}$ for straw) and is:

$$
\beta=\alpha \mathrm{A}_{1} /\left(\alpha \mathrm{A}_{1}+(1-\alpha) \mathrm{A}_{2}\right)
$$

114 Then a mixture of $50 \%$ biomass bark corresponds to $61 \%$ ash bark in wheat straw biomass or 115 ash respectively.

Table 1: Measured elemental composition and ash weight percentage of each biomass feedstock.

\begin{tabular}{|c|c|c|c|c|c|}
\cline { 4 - 6 } \multicolumn{1}{c|}{} & \multicolumn{2}{c|}{ Norm } & straw & bark & MP2b \\
\cline { 4 - 6 } \multicolumn{1}{c|}{} & Relative & \multicolumn{3}{c|}{ uncertainty } & \multicolumn{3}{c|}{} \\
\hline $\mathbf{C}$ & NF EN 15104 & $\pm 1 \%$ & 43.60 & 48.60 & 46.10 \\
\hline $\mathbf{H}$ & NF EN 15104 & $\pm 2 \%$ & 5.50 & 5.80 & 5.65 \\
\hline $\mathbf{O}$ & By difference & & 47.27 & 41.37 & 44.29 \\
\hline $\mathbf{N}$ & NF EN 15104 & $\pm 15 \%$ & 0.54 & 0.60 & 0.57 \\
\hline $\mathbf{C a}$ & NF EN ISO 16967 & $\pm 5 \%$ & 0.29 & 2.56 & 1.43 \\
\hline $\mathbf{K}$ & NF EN ISO 16967 & $\pm 5 \%$ & 1.43 & 0.26 & 0.85 \\
\hline Si & ICP internal method & $\pm 5 \%$ & 0.99 & 0.48 & 0.74 \\
\hline $\mathbf{S}$ & EN 15289 & $\pm 15 \%$ & 0.09 & 0.04 & 0.07 \\
\hline $\mathbf{C l}$ & EN 15289 & $\pm 15 \%$ & 0.14 & 0.01 & 0.07 \\
\hline
\end{tabular}




\begin{tabular}{|c|c|c|c|c|c|}
\cline { 2 - 3 } $\mathbf{P}$ & NF EN ISO 16967 & $\pm 5 \%$ & 0.07 & 0.03 & 0.05 \\
\hline $\mathbf{A l}$ & NF EN ISO 16967 & $\pm 5 \%$ & 0.00 & 0.07 & 0.04 \\
\hline $\mathbf{M g}$ & NF EN ISO 16967 & $\pm 5 \%$ & 0.05 & 0.07 & 0.06 \\
\hline $\mathbf{F e}$ & NF EN ISO 16967 & $\pm 5 \%$ & 0.01 & 0.03 & 0.02 \\
\hline $\mathbf{N a}$ & NF EN ISO 16967 & $\pm 5 \%$ & 0.02 & 0.01 & 0.02 \\
\hline $\mathbf{M n}$ & NF EN 15297 & $\pm 10 \%$ & 0.00 & 0.07 & 0.04 \\
\hline $\mathbf{A s h} \mathbf{5 5 0} \mathbf{~}^{\circ} \mathbf{C}$ & NF EN 14775 & $\pm 5 \%$ & 6.3 & 9.7 & 6.7 \\
\hline
\end{tabular}

\subsection{Experimental setup}

119 Three types of tests were applied. The first two tests (ash test (A) and pellet test (P)) were

120 already described in the work of Defoort et al. [27] and are reminded below:

121 1. Ash test (A) in which biomass pellets $(1.5 \mathrm{~cm} \times 0.5 \mathrm{~cm})$ were heated at $550^{\circ} \mathrm{C}$ for $2 \mathrm{~h}$ in static atmospheric conditions in a Nabertherm LT 15/11/330 furnace then cooled down to room temperature. This step at $550^{\circ} \mathrm{C}$ helped to get rid of all organic oxygen and hydrogen (along with organic nitrogen and part of chlorine) while preserving the majority of the other elements. Afterwards $0.5 \mathrm{~g}$ of ash were compressed as ash chips (1.3 cm diameter) under a pressure of 10 bar to favor the contact between the inorganic particles. The compressed ash chip was put in a 95-5 wt.\% Pt-Au crucible - this material was selected to avoid any interaction between the sample and the crucible - and was heated in a vertical Nabertherm RT 50-250/13 furnace in static atmospheric conditions at a heating rate of $10^{\circ} \mathrm{Cmin}$ until the setpoint temperature was reached. Residence time in Table 2 started to be counted when the final temperature was reached. At the end of each experiment, samples were quenched in the air $\left[\right.$ i.e. $\left.\sim 5^{\circ} \mathrm{C} / \mathrm{s}\right]$ until room temperature. These laboratory conditions favor chemical equilibrium (strong proximity of ash grains).

2. Pellet test $(\mathrm{P})$ where biomass pellets $(1.5 \mathrm{~cm} \times 0.5 \mathrm{~cm})$ were heated directly in a Nabertherm LT 15/11/330 furnace in static atmospheric conditions at a heating rate of $10^{\circ} \mathrm{C} / \mathrm{min}$ until the setpoint temperature was reached. Residence time started to be counted when the 
setpoint temperature was reached. At the end of each experiment, samples were quenched in the air [i.e. $\sim 5^{\circ} \mathrm{C} / \mathrm{s}$ ] until room temperature. These laboratory conditions simulate the conditions in a pilot reactor (low proximity of ash grains dispersed in the biomass matrix).

3. Pilot test (Pilot) where biomass pellets $(1.5 \mathrm{~cm} \times 0.5 \mathrm{~cm})$ were burned. $10 \mathrm{~kg} / \mathrm{h}$ of the biomass pellets were combusted in a $30 \mathrm{~kW}$ Guntamatic Powercom moving bed boiler for $5 \mathrm{~h}$. In addition, $5 \mathrm{~kg} / \mathrm{h}$ of biomass pellets were combusted in a $25 \mathrm{~kW}$ Multiheat 2.5 fixed bed furnace for $2 \mathrm{~h}$. Three thermocouples were inserted in the furnace of the fixed bed reactor to measure the temperature during the test. The same compressed biomass pellets of the 50:50 mixture (MP2b) that were used in the pellet test were applied in the two pilot reactors. Temperature and residence time varied in each laboratory test as indicated in Table 2. Cooling rate (slow cooling [i.e. $\sim 0.05^{\circ} \mathrm{C} / \mathrm{s}$ ] versus quenched cooling [i.e. $\sim 5^{\circ} \mathrm{C} / \mathrm{s}$ ]) was varied for just

151 the ash test at $1000^{\circ} \mathrm{C}$ and $6 \mathrm{~h}$, while quenching was applied in all the other experiments. Each

152 test was performed in duplicate. The oven for the pellet test was not able to reach $1200^{\circ} \mathrm{C}$

153 (maximum operating temperature of $1000^{\circ} \mathrm{C}$ ).

154 An external k-type thermocouple was introduced in the Nabertherm LT 15/11/330 used in the 155 pellet test and the Nabertherm RT 50-250/13 used in the ash test. It was found that the 156 measured temperature in both furnaces in early residence times was different from the final 157 set point temperature by $\pm 20^{\circ} \mathrm{C}$. Hence, ash and pellet test experiments at 20 minutes 158 residence were slightly more inaccurate in terms of operating temperature. However, due to 159 the high-applied temperature range and the small temperature deviation, the results were still 160 considered as being acceptable. 


\begin{tabular}{|c|c|c|c|c|c|c|c|c|c|}
\hline & $20 \mathrm{~min}$ & $1 \mathrm{~h}$ & $2 h$ & $3 h$ & $4 h$ & $5 h$ & $6 h$ & $24 h$ & $40 h$ \\
\hline $850^{\circ} \mathrm{C}$ & $\mathrm{P}$ & $\mathrm{P}$ & & & & & A & A & \\
\hline $1000^{\circ} \mathrm{C}$ & $A \& P$ & $A \& P$ & & A & $\mathrm{A}$ & A & A \& P & & A \\
\hline $1200^{\circ} \mathrm{C}$ & A & A & A & A & & & A & & \\
\hline 2.3. & Anal & inst & & & & & & & \\
\hline
\end{tabular}

Bruker D8 Advance Powder X-Ray diffraction (P-XRD) with $\mathrm{Cu} \mathrm{K \alpha}(40 \mathrm{kV}$ and $30 \mathrm{~mA})$ was used to analyze qualitatively and quantitatively the various solid phases present in the samples along with the amorphous content. Samples were manually ground by a mortar and placed in an amorphous silica sample holder then flattened with glass to obtain a well-defined surface.

168 Diffractograms were obtained over a $2 \theta$ interval between $15^{\circ}$ and $70^{\circ}$. Identification along with

169 semi-quantification of the crystalline phases was first performed using Bruker EVA software 170 along with its I/Icor module. The Diffractograms of all the samples are shown in the appendix.

171 However, instead of the simple semi-quantification using $\mathrm{I} / \mathrm{I}_{\text {cor }}$ modulus in EVA software as

172 proposed in the work of Defoort et al. [27], full XRD quantification was conducted by applying

173 Rietveld refinement to each sample using Panalytical Instruments Highscore plus software after

174 adding 10 wt.\% of $\mathrm{TiO} 2$ Anatase (99.99 wt.\%, Sigma-Aldrich) as an internal standard to 175 quantify the amorphous phase (assumed to be solidified liquid silica-rich phase). Taking into 176 consideration the high operating temperature of $850^{\circ} \mathrm{C}, 1000^{\circ} \mathrm{C}$, and $1200^{\circ} \mathrm{C}$, the majority of

177 the organic materials (chars) should have decomposed and volatilized into the gaseous phase.

178 Hence, their concentration was assumed to be negligible in the amorphous phase in this work.

179 ICDD 2020 crystallography database was used in the two aforementioned software. 
180 For the quantification of the amorphous phase, $10 \mathrm{wt} . \%$ of $\mathrm{TiO}_{2}$ Anatase powder was crushed,

181 manually ground, and mixed with the sample in a way to fill the sample holder $(\sim 0.25 \mathrm{~g}$ total

182 mass of sample and $\mathrm{TiO}_{2}$ standard in each analysis). Hence, the Rietveld analysis for the

183 diffractogram of the XRD of each sample gave the weight percentage of all the crystalline

184 phases in the presence of $\mathrm{TiO}_{2}$ Anatase (standard). To get the amorphous percentage and the

185 real percentage of the other crystalline phases (i.e. in the pure sample without Anatase), the real

186 total weight of the pure sample (i.e. without $\mathrm{TiO}_{2}$ Anatase) $(\mathrm{T})$ needs to be calculated from the

187 XRD measurements by the proportionality rule, as follow:

$$
T=P_{X R D, \text { Anatase }} x \frac{100-P_{m, \text { Anatase }}}{P_{m, \text { Anatase }}}
$$

189

190

With $\mathrm{P}_{\mathrm{XRD}}$, Anatase is the weight percentage of $\mathrm{TiO}_{2}$ Anatase measured by the XRD in the total sample.

$\mathrm{P}_{\mathrm{m}, \text { Anatase }}$ is the measured weight percentage of $\mathrm{TiO}_{2}$ Anatase (standard) used in the total sample, which was $10 \mathrm{wt} . \%$.

Then, the real weight percentage of each phase $\mathrm{i}$ in the pure sample (i.e. without $\mathrm{TiO}_{2}$ Anatase) $\left(\mathrm{p}_{\mathrm{i}}\right)$ was calculated as follow:

$$
p_{i}=\frac{P_{X R D, i}}{T} \times 100
$$

With $\mathrm{P}_{\mathrm{XRD}} \mathrm{i}$ is the weight percentage of phase $\mathrm{i}$ measured by XRD in the total sample (i.e. sample \& $\mathrm{TiO}_{2}$ Anatase).

Then, the amorphous weight percentage (A) was calculated by simple difference:

$$
A=100-\sum p_{i}
$$

200 Each quantification was performed twice. The average relative error corresponding to the 201 Rietveld analysis was around 5\%. Since, the P-XRD analysis was conducted on ash samples, 
the results calculated by the mixing rule in the following Figures of the 50-50 wt.\% bark-straw biomass mixture will always correspond to 61-39 wt.\% bark-straw ash mixture.

\subsubsection{SEM-EDX analysis}

The tendency to form an amorphous phase together with an analysis of the inorganic semiquantitative composition of specific samples was evaluated using a Philips XL30 scanning electron microscopy (SEM) equipped with an energy dispersive X-ray fluorescence Oxford Instruments EDX system (INCA software). For the latter, both surface mapping and point analyses were used. Ash test samples of MP $2 \mathrm{~b}$ at $1200^{\circ} \mathrm{C}$ for $20 \mathrm{~min}$ and $6 \mathrm{~h}$ were embedded

210 under vacuum in epoxy resin then were polished with water-free lubricants. A graphite coating 211 was applied to each sample to increase its conductivity, before the analysis.

\subsubsection{Sieving measurements}

213 Particles sieving was performed in the ashes collected after the pellet test and the pilot tests.

214 For the pellet test the particle size was measured after putting the ashes in a box, which was 215 shaken for about $1 \mathrm{~min}$ to break the loose bridges between particles characterizing their 216 tendency to agglomerate as they could have been done in a pilot test, a method inspired by 217 Steenari et al. [38]. Particle sizes were chosen in the following decreasing order: $4500 \mu \mathrm{m}, 2500$ $218 \mu \mathrm{m}, 900 \mu \mathrm{m}$, and $630 \mu \mathrm{m}$. The particles which size was bigger than $900 \mu \mathrm{m}$ referred to total 219 agglomerates while the ones which size was smaller than $630 \mu \mathrm{m}$ were in the solid phase. 220 Particles which size was bigger than $2500 \mu \mathrm{m}$ were considered as significant agglomerates. The 221 mass fraction in between these meshes was considered to be partially sintered.

222 For the pilot test, the ashes were collected sieved with the same mesh than for the pellet test, 223 weighed to get the weight percentage, then P-XRD measurements were done for the phases 224 present in each particulate size fraction. Using the weight percentage and the crystalline composition of each fraction, a simple mass balance (mixing rule) was conducted to obtain the

226 average pilot-scale proportion of crystalline and amorphous phases. 


\section{Results and discussion}

\subsection{Chemical reaction in comparison with simple mixing effects in the} laboratory ash and pellet tests

The P-XRD results on mineralogical compositions after annealing in the ash test (i.e. using compressed ash chips) and after combustion in the pellet test (i.e. using biomass pellets) at $1000^{\circ} \mathrm{C}$ for $6 \mathrm{~h}$ are presented in Figure 1 for pure straw, pure bark, and their $50-50$ wt. $\%$ biomass mixture (called MP2b). Straw ash in the pellet test melted and interacted within the alumina crucible (Figure A1), so their P-XRD measurements were not possible. In this case, the concentrations of the phases found when pure straw was used in the pellet test were estimated based on the results of pure straw in the pilot fixed bed reactor and in the ash test. Since the PXRD analysis was conducted on ash samples in both tests, the 50-50 mixing rule in this Figure corresponded to a 61-39 bark-straw ash mixture $(\beta)$.

The ash of the single fuels reacts at high temperature in combustion reactors [5]. However, the main focus in this work was on the reaction within the ash of the fuel mixtures. The mechanism of reactions are so complex and highly depend on the ash composition and the operating conditions $[5,6,28]$. Nevertheless, since the ash used in this work were mostly composed of $\mathrm{Si}, \mathrm{Ca}$, and $\mathrm{K}$ (Table 1), chemical reactions, if taking place, will be governed by

244 the interactions between these three elements in the form of oxides. Si exists in the original 245 biomass in the amorphous $\mathrm{SiO}_{2}-\mathrm{H}_{2} \mathrm{O}$ form or in the $\mathrm{Si}(\mathrm{OH})_{4}$ form dissolved in the biomass 246 fluids [5,6]. During combustion or gasification, $\mathrm{H}_{2} \mathrm{O}$ will evaporate and $\mathrm{SiO}_{2}$ will be liberated as small silica particles $\left(\mathrm{SiO}_{2}\right)$ due to its higher affinity to oxygen than hydrogen or carbon 248 along with its refractory characteristics [6]. Alkali metals (i.e. $\mathrm{K}$ and $\mathrm{Na}$ ) are the less stable oxides and may be reduced by the carbon-hydrogen fuel matrix to metal vapor in the form of

$250 \mathrm{KOH}$ and $\mathrm{NaOH}[6]$. Hence, they can react with the silicates in the matrix following an acid251 base reaction to form alkali-silicate oxides [6]. The low eutectic temperatures of the K-Si 
system, that can be as low as $600^{\circ} \mathrm{C}$, makes the formation of agglomerates much easier.

Depending on the ash composition of the fuel and in the case of high availability of $\mathrm{K}$ in the form of $\mathrm{KOH}$, the density of molten potassium-silicates particles increases significantly. But as the fuel particles are burning out, it shrinks and the ash particles approach each other with an increasing opportunity for contact $[6,28]$. This will lead to an aggregation of the molten potassium-silicate particles, which will form a larger droplets and initiate slag formation. This explains the abundance of the amorphous phase in the straw samples (Figure 1) since around $80 \mathrm{wt} . \%$ of the ash of this fuel were composed of Si and K compared to $20 \mathrm{wt} . \%$ in bark ash

260 (Table 1). For instance, the results in Figure 1 showed that straw produced ash with high 261 amount of amorphous phase (assumed to be solidified silicate liquid) in both ash and pellet 262 tests at $1000^{\circ} \mathrm{C}$ (i.e. around $\left.97 \mathrm{wt} . \%\right)$.

263 Fuels, such as woody biomasses, are concentrated with alumina-silicates and calcium-silicates 264 compounds [4]. From Table 1, bark ash contained 71 wt.\% calcium compared to 9 wt.\% in 265 straw ash. During thermochemical conversion of biomass, the aluminosilicates and calcium266 silicates compounds will be probably liberated from the ash matrix as small micrometered267 sized particles. This will increase the refractory character of the ash matrix; hence, most of it 268 will remain in the solid form. These compounds are highly stable and have the potentials to 269 increase the melting temperature of the ash [6]. Accordingly, from the results in Figure 1, in 270 the ash test, bark produced ash-rich in solid $\mathrm{CaO}\left(47\right.$ wt.\%) and $\mathrm{Ca}_{2} \mathrm{SiO}_{4}(21$ wt.\%) along with 271 around just $20 \mathrm{wt} . \%$ of amorphous phase. $\mathrm{K}_{2} \mathrm{Ca}_{6} \mathrm{Si}_{4} \mathrm{O}_{15}$ was totally absent in the bark ash of 272 the pellet test (it was just $1.8 \mathrm{wt} . \%$ in the ash test) with slightly higher concentrations of $\mathrm{CaO}$ 273 (53 wt.\%) and amorphous phase (22 wt.\%) and lower concentration of $\mathrm{Ca}_{2} \mathrm{SiO}_{4}(11 \mathrm{wt} . \%)$ 274 than in the ash test. Hence, negligible differences were noticed between the two tests in the 275 case of single biomasses. 
Chemical reactions within the ash were more apparent when fuels were mixed. The chemical composition of the feedstock was significantly altered upon mixing, which was reflected for example in the change of the calcium over alkali-silicates ratio from 0.1 in the straw and 3.5 compounds, can encounter the earth alkali oxide that are mostly concentrated in the bottom ash $[6,28,29]$. Competition between the earth metals $(\mathrm{Ca}, \mathrm{Mg})$ and $\mathrm{K}$ on the active sites of the silicate matrix lead to a substitution of $\mathrm{K}$ in this matrix by $\mathrm{Ca}$ and $\mathrm{Mg}$. This incorporation of earth metals into the agglomerates, due to the high affinity of silicate melts to earth metals [6], increases the melting temperature of the ash and decreases the agglomeration propagation.

Several authors showed several reaction pathways for this incorporation leading to more stable compounds that were seen in several studies concerning combustion of biomass, such as $\mathrm{Ca}_{2} \mathrm{~K}_{2} \mathrm{Si}_{9} \mathrm{O}_{21}$ in the work of Rebling et al. [28] and $\mathrm{K}_{2} \mathrm{Ca}_{6} \mathrm{Si}_{4} \mathrm{O}_{15}$ and $\mathrm{K}_{2} \mathrm{Ca}_{2} \mathrm{Si}_{2} \mathrm{O}_{7}$ in the work of Santoso et al. [29].

In this work, when straw (rich in alkali-silicate oxides) was mixed with bark (rich in earth

290 alkali oxides), two ternary phases $\mathrm{K}_{2} \mathrm{Ca}_{6} \mathrm{Si}_{4} \mathrm{O}_{15}(\mathrm{O} 15)$ and $\mathrm{K}_{2} \mathrm{Ca}_{2} \mathrm{Si}_{2} \mathrm{O}_{7}(\mathrm{O} 7)$ appeared in the 291 measured mixture in the ash test. They were not present in the single biomass trials. In parallel, in the ash test, in contrast with the mixing law results (i.e. mixing without chemical interaction), $\mathrm{CaO}$ and $\mathrm{CaSiO}_{3}$ were absent in the measured $\mathrm{XRD}$ results of the mixture (Figure

294 1). Furthermore, the proportion of the existing phases in the single biomass combustion trials, 295 such as $\mathrm{Ca}_{2} \mathrm{SiO}_{4}$ (in bark) and $\mathrm{K}_{2} \mathrm{SO}_{4}$ (in straw), slightly decreased in the mixture, and 296 therefore did not follow the mixing rule. Most importantly, the proportion of the amorphous 297 phase in the ash test, when following the mixing rule without chemical reaction, should be 298 theoretically 50 wt.\% in the mixture. However, its contents was measured by the P-XRD to be 29925 wt.\% (Figure 1). Consequently, the presence of chemical reactions within the ash of the 300 biomass mixture in the ash test was confirmed and was dominant over the mixing rule effects. 
301 The reactions affected the ash behavior of the biomass mixture by decreasing the amorphous

302 contents beyond the amount predicted by the mixing rule. Hence, biomass mixing can indeed

303 affect the ash behavior through various reactions, which need to be effectively mastered and

304 predicted.

305 Lower proportions of $\mathrm{O} 7$ and $\mathrm{O} 15$ were found in the pellet test than in the ash test 306 measurements, similar to the results of Defoort et al. [27]. This was the direct consequence of 307 the higher reactivity in the ash test than in the pellet test. Using compressed ash chips, the ash 308 test provided higher physical proximity between inorganic constituents, which was thought to 309 enhance the reactions. Potassium might have reacted with calcium on the silicate matrix instead 310 of volatilizing, to form the new ternary solid phases instead of the amorphous phase [6]. On the 311 contrary, the reaction in the pellet test was less marked due to the presence of organic materials, 312 which evaporated during combustion and left a higher porosity in the sample (i.e. lower grain 313 proximity).

314 Unreacted $\mathrm{CaO} / \mathrm{Ca}(\mathrm{OH})_{2}$ is considered as the main crystal product in single bark ash (Figure 1) 315 and as a direct reactant in $\mathrm{K}_{2} \mathrm{Ca}_{6} \mathrm{Si}_{4} \mathrm{O}_{15}$ formation. Hence, its presence in mixture samples' 316 reflects a low reactivity level between the inorganic particles in the mixtures. It was observed 317 that $\mathrm{CaO} / \mathrm{Ca}(\mathrm{OH})_{2}$ did not transform in the pellet test in the mixture as was the case in the ash 318 test. This means that the bark ash did not fully react with the straw ash when the pellet test was 319 used instead of the ash test. Furthermore, the proportion of the amorphous phase in the pellet 320 test mixture case was close to the one predicted by the mixing rule i.e. without reaction effect 321 between the two biomasses (71 wt.\% measured by P-XRD vs 50 wt.\% calculated by the mixing 322 rule). Measured $\mathrm{Ca}_{2} \mathrm{SiO}_{4}$ and $\mathrm{CaO} / \mathrm{Ca}(\mathrm{OH})_{2}$ in the pellet test were also successfully predicted 323 by the mixing rule. Hence, contrary to the ash test and despite the presence of chemical 324 reactions, mixing rule effects were dominant in the pellet test. 


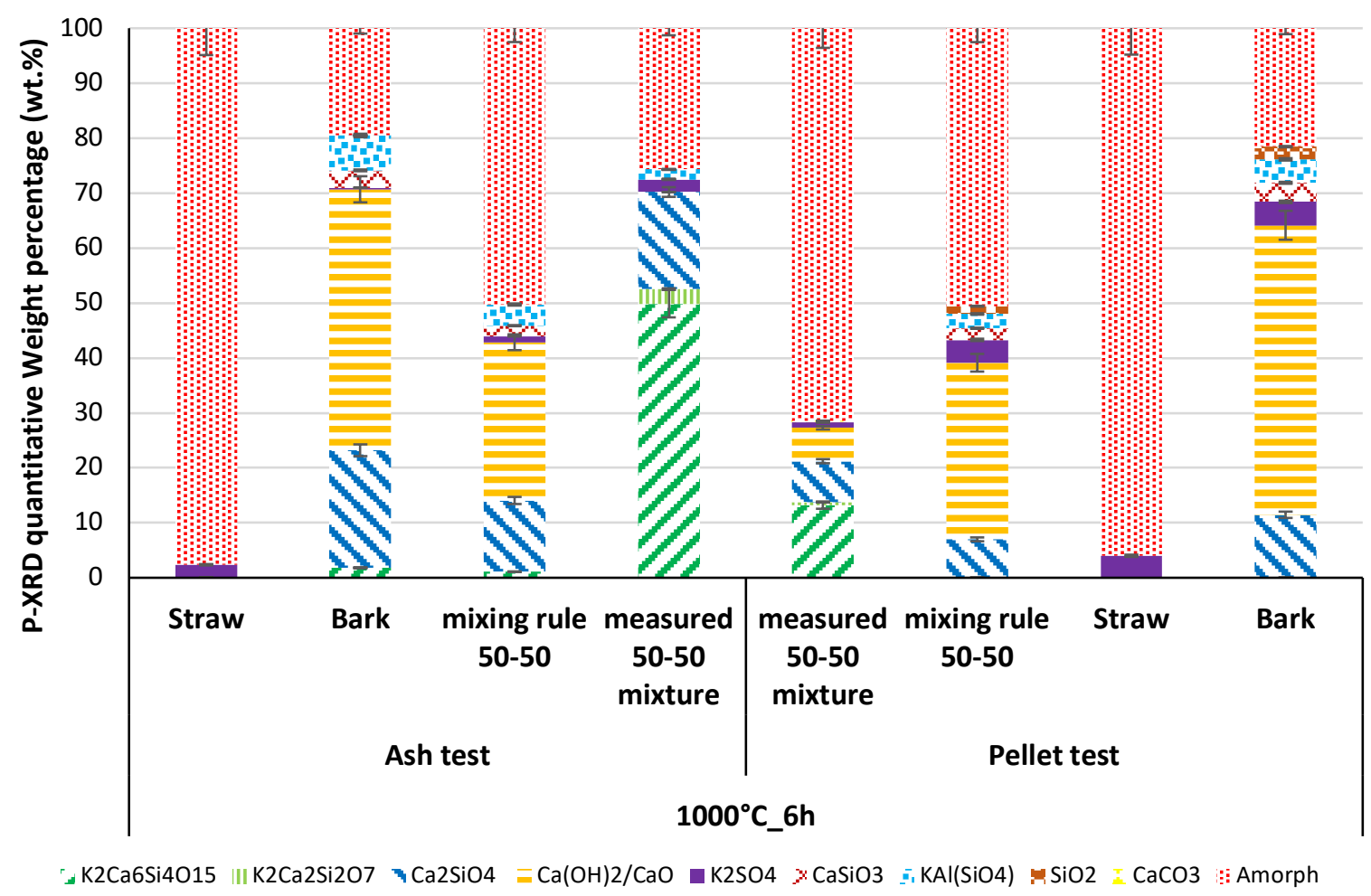

Figure 1: $P-X R D$ analysis of single oak bark, single wheat straw, and their mixture at $1000^{\circ} \mathrm{C}$ after $6 \mathrm{~h}$ in the laboratory ash and pellet tests.

329 The variation of the crystalline and amorphous proportions in MP2b as a function of residence

330 time and temperature are shown in Figures 2 and 4 for the ash and the pellet tests, respectively.

331 For the ash test, long residence times were selected to check if there was a stabilization of the

332 mineralogical composition, i.e. to check if equilibrium was reached (no mass transfer versus

333 time). For the pellet test, no equilibrium was expected due to the significantly lower reactivity

334 between the loose ash particles, as already discussed in section 3.1. Hence, temperature and

335 short residence time close to the ones encountered in the pilot-scale reactors were studied in the

336 pellet test. The impact of the observed cooling rates on the final mineralogical compositions

337 between slow $\left(\sim 0.05^{\circ} \mathrm{C} / \mathrm{s}\right)$ and fast $\left(\sim 5^{\circ} \mathrm{C} / \mathrm{s}\right)$ cooling in ash test was negligible. Defoort et al.

338 [27] showed in their work that the pelletizing parameters (pellet compression rate) also did not

339 have any effect on the ash reactivity. 
341 In the ash test, the proportion of $\mathrm{K}_{2} \mathrm{Ca}_{2} \mathrm{Si}_{2} \mathrm{O}_{7}$ (light green) increased 4 wt. $\%$ at $850^{\circ} \mathrm{C}$ while it 342 decreased from 13 wt. $\%$ to 1 wt. $\%$ at $1000^{\circ} \mathrm{C}$ (Figure 2 ) with the increase in residence time. It 343 should be noted that drawing clear conclusions at $850^{\circ} \mathrm{C}$ is limited due to the few experimental 344 points (just two experimental conditions for $6 \mathrm{~h}$ and $24 \mathrm{~h}$ ). However, more experimental points 345 at $1000^{\circ} \mathrm{C}$ compensated this limitation, and adding the two experimental points at $850^{\circ} \mathrm{C}$ 346 contributed to the demonstration of the overall ash behavior with respect to temperature and 347 residence time variation. The amount of $\mathrm{K}_{2} \mathrm{Ca}_{6} \mathrm{Si}_{4} \mathrm{O}_{15}$ (dark green) exhibited a parabolic 348 behavior that peaked at around $50 \mathrm{wt} . \%$ (i.e. equilibrium is reached when mass transfer ceased) 349 at $1000^{\circ} \mathrm{C}$ and $5 \mathrm{~h}$ to $6 \mathrm{~h}$, conditions that were considered as optimum for this type of mixture. 350 The increase in $\mathrm{O} 15$ at the expense of $\mathrm{O} 7$ proportions at $1000^{\circ} \mathrm{C}$ in this work supports the 351 reactant-product reversible reaction pathway between these two crystalline structures, as 352 presented in the work of Santoso et al. [29]. In their work, Santoso et al. suggested the reaction 353 of $\mathrm{K}_{2} \mathrm{Ca}_{2} \mathrm{Si}_{2} \mathrm{O}_{7}$ with calcium-silicate compounds to produce $\mathrm{K}_{2} \mathrm{Ca}_{6} \mathrm{Si}_{4} \mathrm{O}_{15}$ [29]. The formation 354 of this phase, either from the aforementioned possible reaction or from the reaction of the 355 calcium earth metals in the bark with the potassium-silicates in the straw, decreased the 356 available amount of silicates that can react with potassium, hence in turn can limit the 357 amorphous phase formation. This was indeed confirmed from the results in Figure 2 where the 358 appearance of $\mathrm{K}_{2} \mathrm{Ca}_{6} \mathrm{Si}_{4} \mathrm{O}_{15}$ was always conjugated with a decrease in the amorphous phase. 359 For instance, the increase of $\mathrm{O} 15$ from 8 wt.\% to 51 wt.\% was conjugated with a decrease in 360 the amorphous concentration from $43 \mathrm{wt} . \%$ to $26 \mathrm{wt} . \%$ as residence time increased from $20 \mathrm{~min}$ 361 to $40 \mathrm{~h}$ at $1000^{\circ} \mathrm{C}$. Hence, when using bark-straw biomass mixture in a furnace or a FB, mixture 362 formulation and reactor operation should be directed in a way to obtain the highest proportion 363 possible of $\mathrm{K}_{2} \mathrm{Ca}_{6} \mathrm{Si}_{4} \mathrm{O}_{15}$. 
364 Similar amounts of $\mathrm{Ca}_{2} \mathrm{SiO}_{4}$ were also present in all samples. Minor proportions of $365 \mathrm{CaO} / \mathrm{Ca}(\mathrm{OH})_{2}$ were observed at $850^{\circ} \mathrm{C}$ and $1000^{\circ} \mathrm{C}$ at short residence times, but this compound 366 was absent at $1000^{\circ} \mathrm{C}$ and long residence times $(5 \mathrm{~h})$ and at $1200^{\circ} \mathrm{C}$. This, in turn, supports the 367 finding that reaction was complete and equilibrium was reached for $1000^{\circ} \mathrm{C}$ at $5 \mathrm{~h}$ and $1200^{\circ} \mathrm{C}$ 368 at around $3 \mathrm{~h}$.

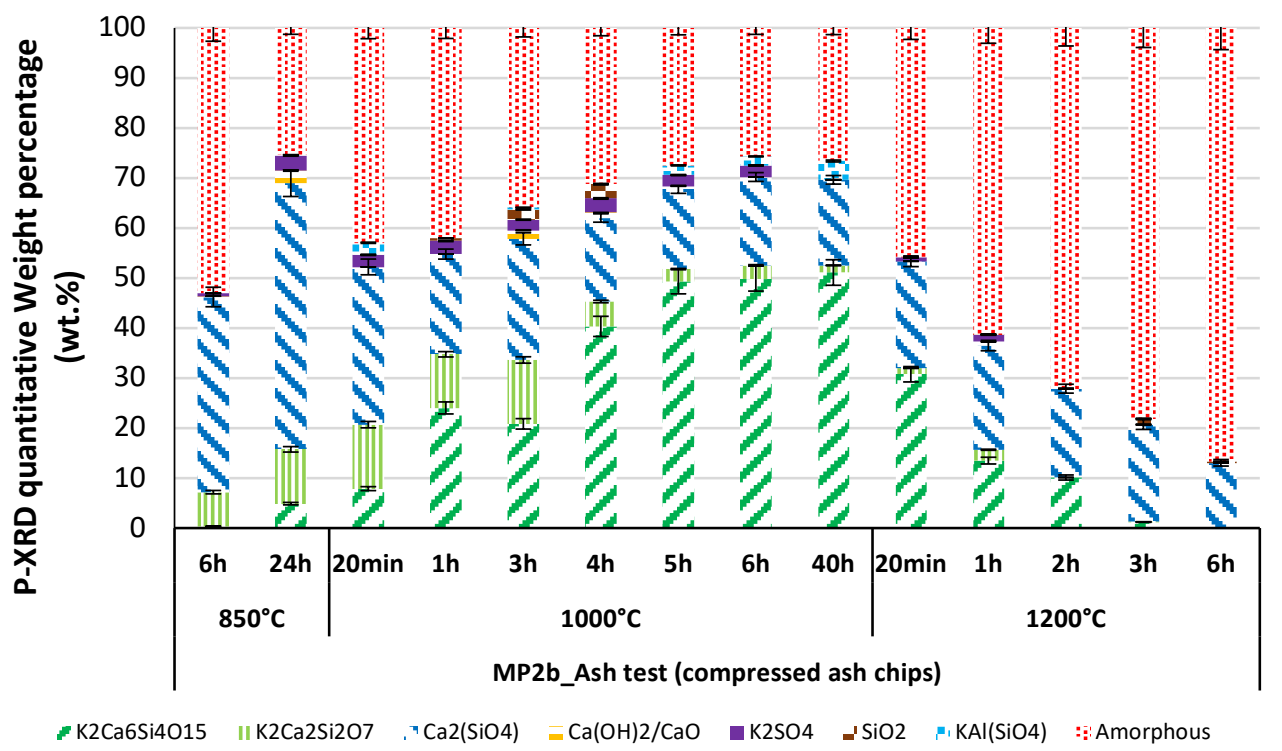

Figure 2: P-XRD results of the ash test at various temperatures and residence times.

As can be seen in Figure 2, with the increase in residence time at $1200^{\circ} \mathrm{C}$, equilibrium was approached after around $3 \mathrm{~h}$, conditions at which $\mathrm{K}_{2} \mathrm{Ca}_{6} \mathrm{Si}_{4} \mathrm{O}_{15}$ and $\mathrm{K}_{2} \mathrm{Ca}_{2} \mathrm{Si}_{2} \mathrm{O}_{7}$ were decomposed. To validate this decomposition, SEM-EDX analysis as presented in Figure 3 showed the variation of the phases at $1200^{\circ} \mathrm{C}$ between $20 \mathrm{~min}$ (Figure 3.a) and 6h (Figure 3.b) in the MP2b biomass mixture for each different shape, and the results were also compared to the ones of Chen et al. [39]. Electron probe X-ray microanalysis (EPMA) techniques were used in their work starting from various mixtures of $\mathrm{CaCO}_{3}-\mathrm{K}_{2} \mathrm{CO}_{3}-\mathrm{SiO}_{2}$ [39]. They provided EPMA pictures for the crystalline phases of interest [39].

Following the results in Figure 2, the ternary phases of interest, $\mathrm{K}_{2} \mathrm{Ca}_{6} \mathrm{Si}_{4} \mathrm{O}_{15}$ and $\mathrm{K}_{2} \mathrm{Ca}_{2} \mathrm{Si}_{2} \mathrm{O}_{7}$, were present at $20 \mathrm{~min}$ in Figure 3.a but absent at $6 \mathrm{~h}$ in Figure $3 . \mathrm{b}$ at $1200^{\circ} \mathrm{C}$. According to the EDX analysis and similarly to the findings of Chen et al. [39], $\mathrm{K}_{2} \mathrm{Ca}_{6} \mathrm{Si}_{4} \mathrm{O}_{15}$ has a rectangular- 
oval shape while $\mathrm{K}_{2} \mathrm{Ca}_{2} \mathrm{Si}_{2} \mathrm{O}_{7}$ looks like long sticks and $\mathrm{Ca}_{2} \mathrm{SiO}_{4}$ was characterized by a circular 383 shape.

384 For the case of 20 min residence time (Figure 3.a), the sample was highly heterogeneous, while 385 the one at $6 \mathrm{~h}$ was characterized by its higher homogeneous propensity. The equilibrium, 386 supported by the P-XRD results in Figure 2, might have affected this varying morphology 387 transforming a heterogeneous structure into a more homogenous one as it was reached. $388 \mathrm{~K}_{2} \mathrm{Ca}_{6} \mathrm{Si}_{4} \mathrm{O}_{15}$ in the 20 minutes sample (Figure 3.a) was highly surrounded by amorphous layers, 389 which refers to its possible disappearance at $1200^{\circ} \mathrm{C}$ with increasing time (i.e. as equilibrium 390 was approached) by fusion and reaction with elements in the liquid phase.

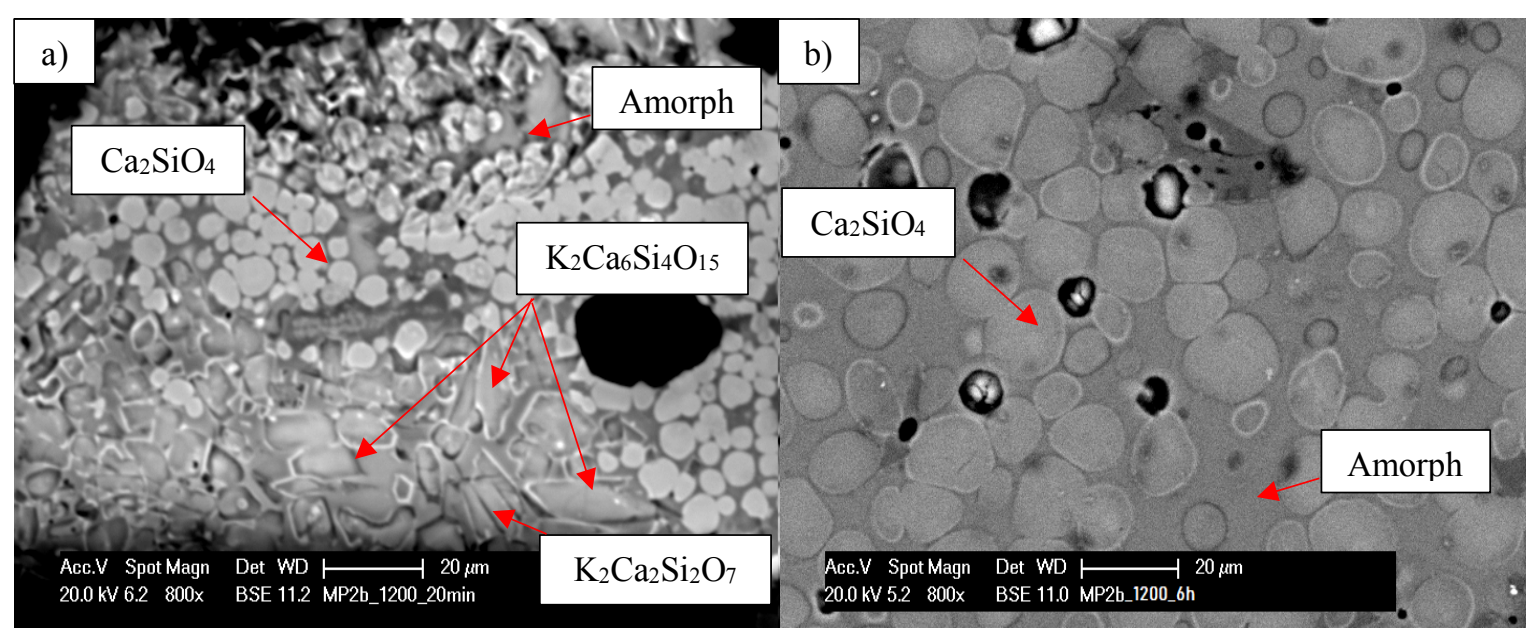

\subsubsection{Pellet test results}

394 Figure 4 shows the P-XRD results of the pellet test using the 50-50 blend under various operating conditions. The two ternary compounds $\mathrm{K}_{2} \mathrm{Ca}_{6} \mathrm{Si}_{4} \mathrm{O}_{15}$ and $\mathrm{K}_{2} \mathrm{Ca}_{2} \mathrm{Si}_{2} \mathrm{O}_{7}$ in the pellet

396 test, as visible in Figure 4, showed similar behavior to those in the ash test with respect to 397 temperature (at $850^{\circ} \mathrm{C}$ and $1000^{\circ} \mathrm{C}$ ) and residence times, but with significantly lower 398 proportions than the ash test. This was due to the lower reactivity in the pellet test, as explained 399 in section 3.1, under the same operating conditions. This lower reactivity was also visible in the 400 negligible change in the amorphous phase proportion and its constant high proportion along 
401 with the constant presence of $\mathrm{CaO}$ under all operating conditions. Hence, due to this lower 402 reactivity level and in contrast with the ash test, the effects of operating conditions on ash 403 reactivity of biomass mixtures in the pellet test were less significant.

404 Though by comparing the composition of the samples between $850^{\circ} \mathrm{C}$ and $1000^{\circ} \mathrm{C}$ at the same 405 residence time (20min then $1 \mathrm{~h}$ ), the mineralogical compositions changed, which can be 406 attributed to an increased reactivity with temperature since $\mathrm{CaCO}_{3}$ present at $850^{\circ} \mathrm{C}$ was 407 calcined to $\mathrm{CaO}$ at $1000^{\circ} \mathrm{C}$ and 20 min then reacted. Four-time less $\mathrm{CaO}$ was found at $1000^{\circ} \mathrm{C}$ 408 after $1 \mathrm{~h}$ while four-time more $\mathrm{K}_{2} \mathrm{Ca}_{6} \mathrm{Si}_{4} \mathrm{O}_{15}$ was found due to chemical reaction, but both with 409 low overall concentrations. Authors of this work doubt that the pellet test will ever reach a 410 complete equilibrium state since the distance between the inorganic particles will never be close 411 enough to each other and due to the presence of the organic matrix in the samples, contrary to 412 the case of the ash test.

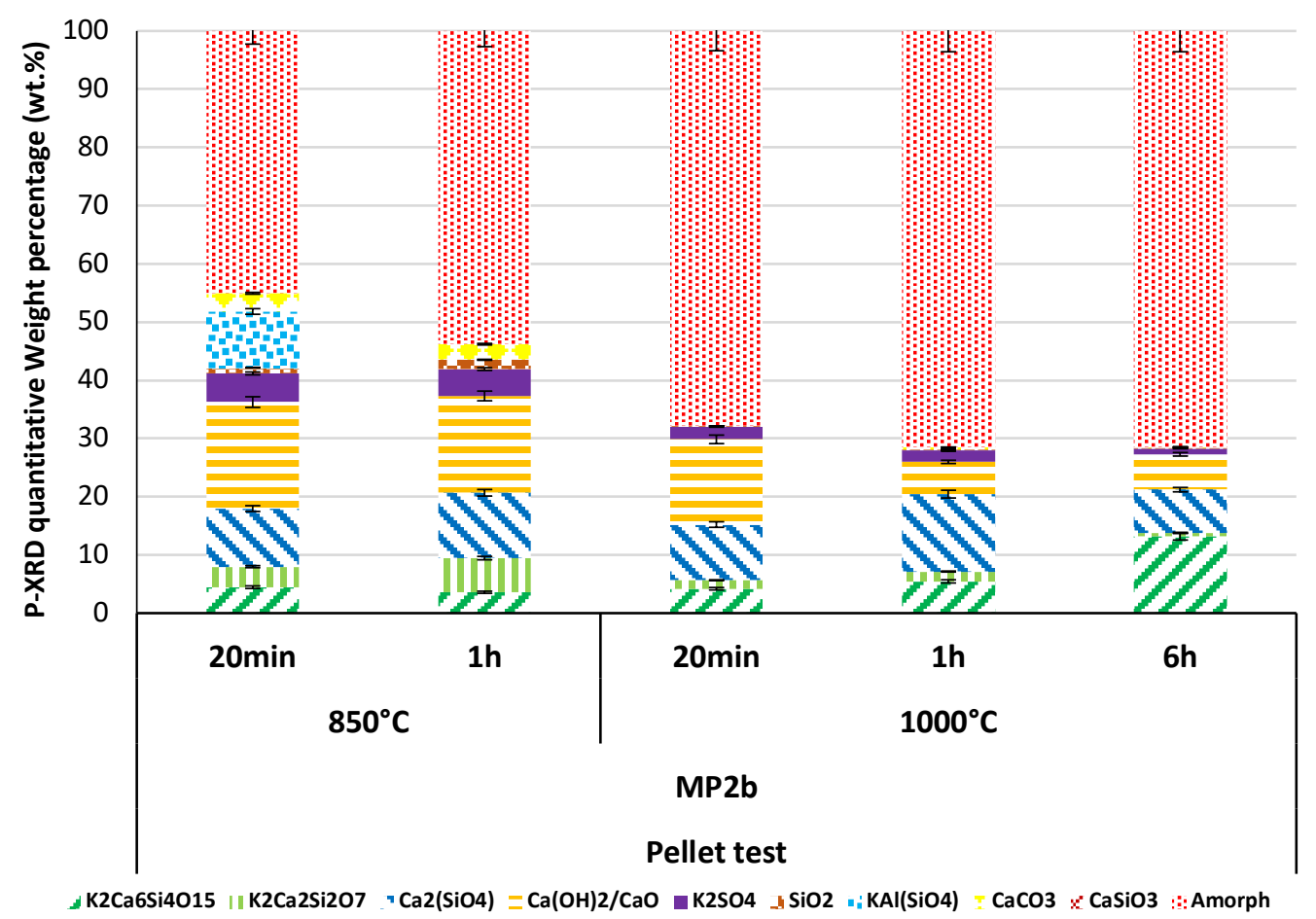


415 Figure 5 shows the sieving fractions of the produced ash from the MP2b mixture under the

416 various operating conditions. Particles smaller than $630 \mu \mathrm{m}$ refer to solid powder whereas

417 those bigger than $900 \mu \mathrm{m}$ are considered as being agglomerates. Agglomerates are considered

418 to be formed of big pieces of amorphous phases entrapping minor amounts of crystalline

419 compounds. Hence, the concentrations of the amorphous phase and the ones of agglomerates

420 are directly correlated and proportional.

421 It can be seen from the results in Figure 5 that in the pellet test for the case of the 50-50

422 biomass mixture, the fraction of the large particle size (agglomerates $>900 \mu \mathrm{m})$ increased with

423 the increase in residence time. It can also be seen that temperature affected the formation of

424 agglomerates by comparing the pellet test between $850^{\circ} \mathrm{C}$ and $1000^{\circ} \mathrm{C}$ under a fixed residence

425 time of $1 \mathrm{~h}$, where large particle size fraction significantly increased from $38 \mathrm{wt} . \%$ to $57 \mathrm{wt} . \%$.

426 In Figure 5, agglomerates' weight fractions above $900 \mu \mathrm{m}$ at $1000^{\circ} \mathrm{C}$ were $60 \mathrm{wt} . \%$ at $20 \mathrm{~min}$,

42755 wt. $\%$ at $1 \mathrm{~h}$, and 83 wt. $\%$ at $6 \mathrm{~h}$. In comparison, from Figure 4, the amorphous phase

428 fraction quantified by P-XRD for the pellet test under the same operating conditions were 68

429 wt.\%, 71 wt.\%, and 71 wt.\%, respectively. Hence, the percentage of errors between the two

430 methodologies were $13 \%, 29 \%$ and $14 \%$, respectively, meaning an error of $18.67 \%$ on

431 average. Taking into account the small sample weights used in the sieving of the pellet test

432 that can induce several measurement errors and the fact that agglomerates entrap a certain

433 amount of crystalline phases, it can be said that both methods can be to a certain extent used

434 for amorphous quantification, with an emphasize on the PXRD-internal standard-Rietveld

435 refinement methodology. 


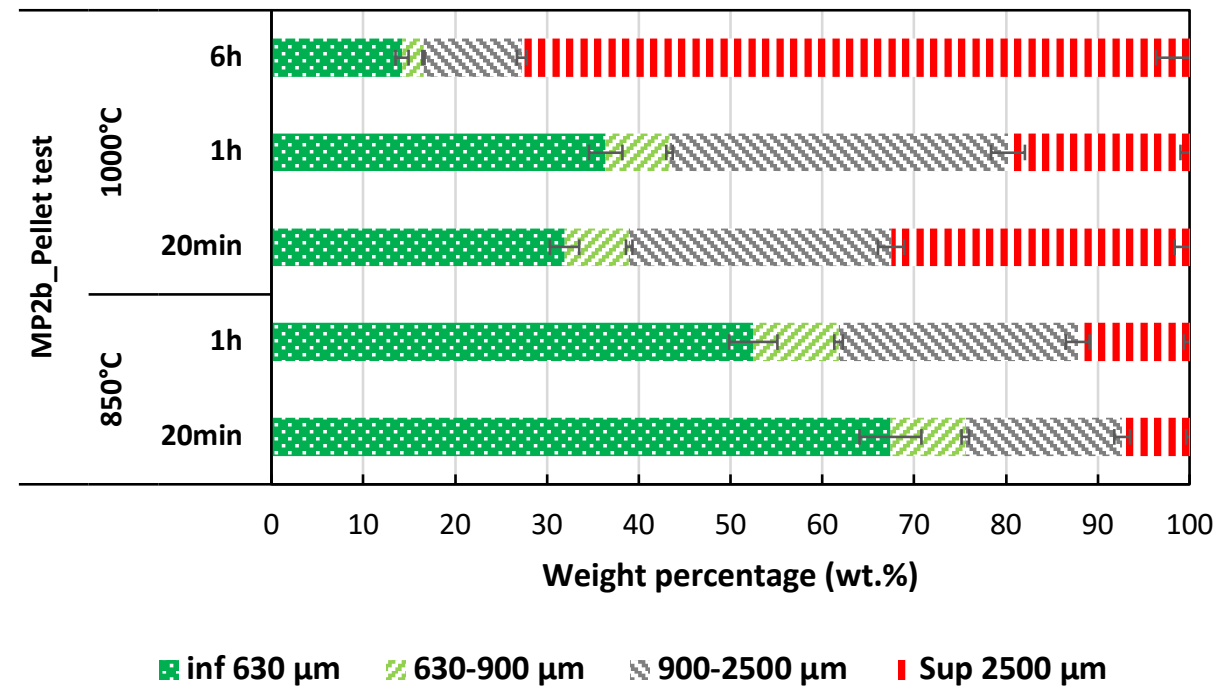

436

Figure 5: Particles size distribution of ash pellet test using MP2b under various operating conditions.

\subsection{Laboratory test results comparison with pilots}

Figure 6 shows the P-XRD results of the ashes collected after the pellet combustion of single biomass (bark, straw) and 50-50 bark-straw mixture in the fixed and moving bed combustion pilots. Moreover this figure shows the results of the mixing rule calculated from the ashes collected from the fixed bed pilot test using each single feedstock.

Temperature measurements results along with gaseous emissions (i.e. $\mathrm{CO}$ and $\mathrm{NO}_{\mathrm{x}}$ ) were shown in the Appendix, but are out of scope in this work. In the moving grid pilot reactor, the temperature was estimated to be in the range of $900^{\circ} \mathrm{C} \pm 20^{\circ} \mathrm{C}$ and the residence time around $20 \mathrm{~min} \pm 3 \mathrm{~min}$. In the fixed bed reactor, residence time was around $2 \mathrm{~h}$, and the combustion temperature was measured and was found to be $700^{\circ} \mathrm{C}$ when wheat straw was applied, $950^{\circ} \mathrm{C}$ when the bark was used, and around $1000^{\circ} \mathrm{C}$ in the case of the blend. $78 \mathrm{wt} . \%$ of the ash of wheat straw was composed of Si and K while 71 wt.\% of bark ash was made of Ca (Table 1). As explained in section 3.1, the high alkali contents will react with the silica matrix and significantly lower the ash melting point [6]. On the other hand, the high calcium contents will stabilize the melting behavior of the ash and increase its melting point [6]. For instance, wheat straw is known to melt between $400^{\circ} \mathrm{C}$ and $960^{\circ} \mathrm{C}$, reaching severe melting at 
temperatures between $680^{\circ} \mathrm{C}$ and $780^{\circ} \mathrm{C}$ [35] while bark is more stable even at a high temperature of $1000^{\circ} \mathrm{C}$ (melting $1060^{\circ} \mathrm{C}-1500^{\circ} \mathrm{C}[23,35]$ ). This was in total accord with the combustion temperatures for straw and bark found in this work. The presence of melts will cause sintering and corrosion inside the burning chamber and hence push the gaseous proportion outside their acceptable toxic range [22,33]. When bark was mixed with straw, Ca contents increased to $42 \mathrm{wt} . \%$ compared to straw, and hence along with the chemical interaction between the inorganic compounds coming from the fuel mixing that created stable ternary phases, increased the combustion temperature of the mixture.

It is observed, in Figure 6, that in the fixed bed pilot, straw was rich in amorphous contents (95 wt.\%) while the bark was more abundant with $\mathrm{CaO}$ (31 wt.\%) and $\mathrm{Ca}_{2} \mathrm{SiO}_{4}$ (21 wt.\%). $\mathrm{K}_{2} \mathrm{Ca}_{2} \mathrm{SiO}_{7}$ (first ternary phase) and $\mathrm{K}_{2} \mathrm{Ca}_{6} \mathrm{Si}_{4} \mathrm{O}_{15}$ (second ternary phase) were absent or negligible in the ash of the single straw and single bark on pilot level. However, $\mathrm{K}_{2} \mathrm{Ca}_{2} \mathrm{SiO}_{7}$ and $\mathrm{K}_{2} \mathrm{Ca}_{6} \mathrm{Si}_{4} \mathrm{O}_{15}$ were both identified in the samples of the biomass mixture after experiments in both pilot reactors. $\mathrm{CaO}$ calculated to be at $22 \mathrm{wt} . \%$ by the mixing rule in the blend was measured at around $5 \mathrm{wt} \%$ in the fixed bed reactor and $7 \mathrm{wt} . \%$ in the moving grid reactor. $\mathrm{Ca}_{2} \mathrm{SiO}_{4}$ and amorphous contents were predicted to be $15 \mathrm{wt} . \%$ and $52 \mathrm{wt} . \%$ by the mixing rule calculation. In comparison, they were measured at $19 \mathrm{wt} . \%$ and $60 \mathrm{wt} . \%$ in the fixed bed reactor and $10 \mathrm{wt} . \%$ and $69 \mathrm{wt} . \%$ in the moving grid pilot reactor. Hence, similarly to the laboratory pellet test experiments, despite the abundance of the mixing effect without interaction, a reaction within the ash took place in both pilot reactors.

Both pilots used the same biomass pellets of the laboratory pellet test. Hence, the pellet test, specifically at $1000^{\circ} \mathrm{C}$ for 20 minutes and $1 \mathrm{~h}$ can be used to possibly simulate/predict the pilotscale ash behavior. Pellet test P-XRD results of $\mathrm{MP} 2 \mathrm{~b}$ at $1000^{\circ} \mathrm{C}$ and $1 \mathrm{~h}$ in Figure 4 were close to the ones measured on pilot scale, recording $71 \mathrm{wt} . \%$ amorphous phase, 5 wt. $\% \mathrm{~K}_{2} \mathrm{Ca}_{6} \mathrm{Si}_{4} \mathrm{O}_{15}$, 5 wt. $\% \mathrm{CaO}$ and 13 wt.\% $\mathrm{Ca}_{2} \mathrm{SiO}_{4}$. Similarly, close phase distributions were exhibited in the 
case of single biomasses by comparing the results in Figures 1 and 6. Consequently, despite the

480 scale increase between the pellet test and the pilots, the pellet test showed great prediction 481 capabilities for the pilots in terms of crystalline and amorphous phases' fractions for both single 482 feedstock and their biomass mixture.

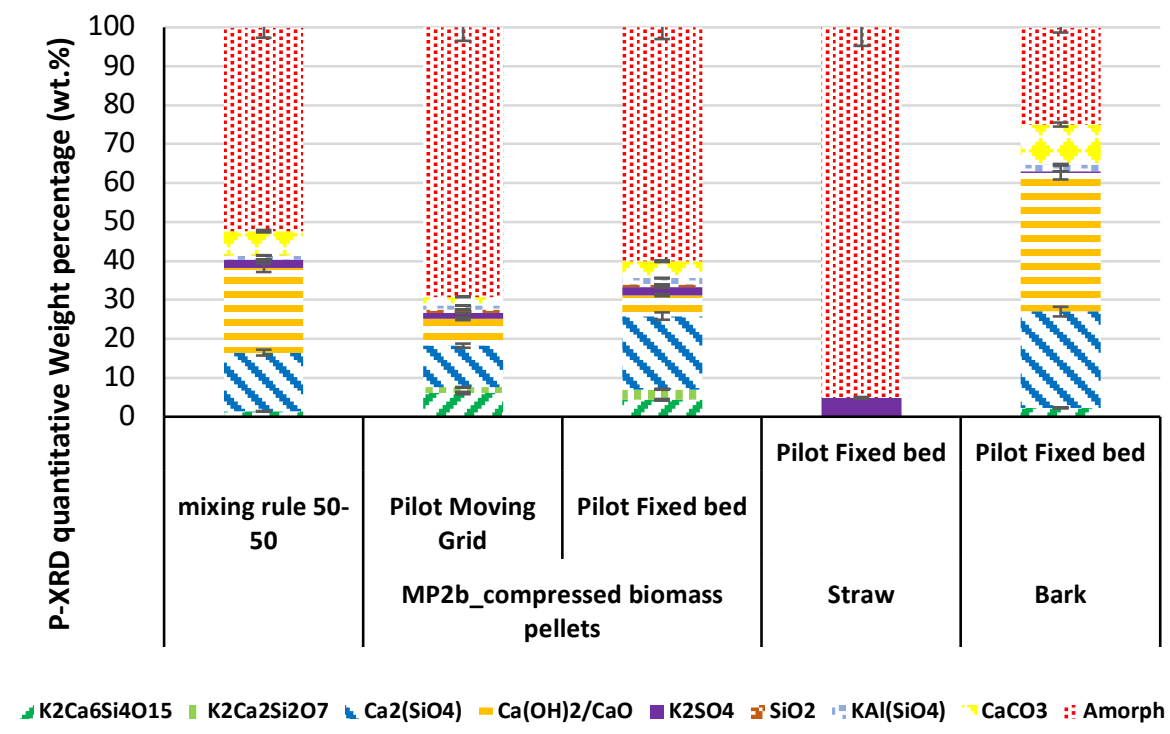

483

484

485

486

487

488

Figure 6: $P-X R D$ average crystalline and amorphous distribution in pilot reactors.

The sieving fractions of the produced ash from the fixed and moving bed reactors were plotted for the single bark, single straw, and MP2b mixture in Figure 7. Furthermore the mixing rule was also calculated from the ashes of the single biomass of the fixed bed reactor and plotted on the same Figure.

Particles smaller than $630 \mu \mathrm{m}$ referred to solid powder whereas those bigger than $900 \mu \mathrm{m}$ are considered as being agglomerates. Straw was problematic if applied in a furnace since more than $75 \mathrm{wt} . \%$ of it showed significant agglomeration $(>2500 \mu \mathrm{m})$ and around $84 \mathrm{wt} . \%$ total agglomeration $(>900 \mu \mathrm{m})$. Bark was ideal for furnace combustion application since more than 60 wt.\% of it remained as a solid powder $(<630 \mu \mathrm{m})$. Without chemical reaction (i.e. mixing rule is valid), significant agglomeration should theoretically be in the range of $47 \mathrm{wt} . \%$ $(>2500 \mu \mathrm{m})$ and total agglomeration around $60 \mathrm{wt} . \%(>900 \mu \mathrm{m})$. However, the presence of 
chemical reactions within the ash of the feedstock mixture further enhanced the decrease of the

497 significant agglomeration to less than $25 \mathrm{wt} . \%,(>2500 \mu \mathrm{m})$ and total agglomeration to around 49850 wt.\% $(>900 \mu \mathrm{m})$, on average. This made the application of straw in the pilot boiler less 499 problematic when mixed with bark.

500 It should be noted that the mass of agglomerate fractions above $900 \mu \mathrm{m}$ of bark, straw, and the 501 biomass mixture of both pilot reactors in Figure 7 were close and proportional to the amorphous 502 phase fraction quantified by PXRD in Figure 6 (95 wt.\% in Figure 6 VS 84 wt.\% in Figure 7 503 for straw, 25 wt.\% in Figure 6 VS 37 wt.\% in Figure 7 for bark, 65 wt.\% in Figure 6 VS 53 504 wt.\% in Figure 7 for the mixtures on average). Hence, both methods can provide amorphous / 505 agglomeration quantification. In parallel, from the sieving fractions of the pellet test at $1000^{\circ} \mathrm{C}$ 506 and $1 \mathrm{~h}$ for the mixture case in Figure 5, total agglomeration was measured to be $57 \mathrm{wt} . \%$ while 507 the one of pilots in Figure 7 was measured to be 53 wt.\% on average. Hence, the pellet test was 508 also able to predict the agglomerates proportion of the pilot reactors.

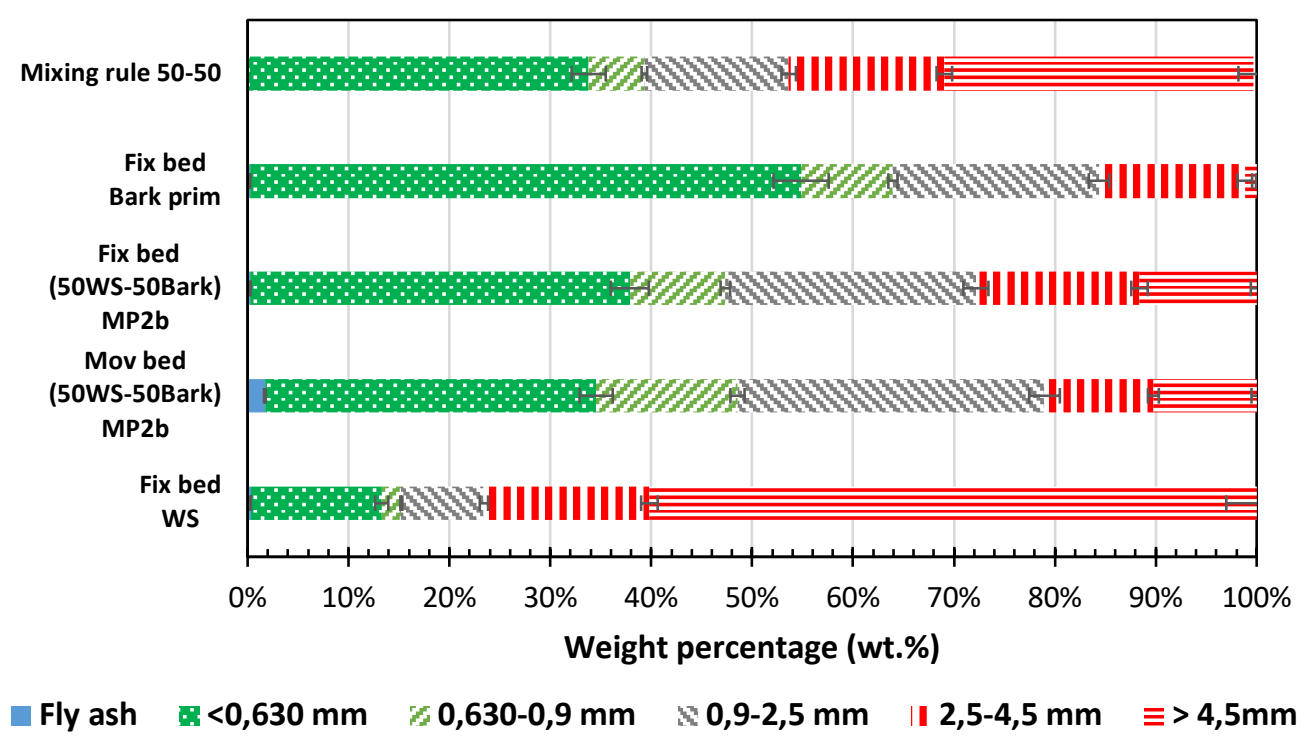


512 Chemical reactions effect was dominant when ash mixtures (i.e. ash test) were used while

513 mixing rule influence was the most important when biomass mixtures were applied on both

514 laboratory (i.e. pellet test) and pilot scales, with only a small chemical reactivity found in the

515 second case. Hence, in terms of tests, ash reactivity can be ranked in the decreasing order as

516 follow: ash test $>$ pellet test $>$ pilot. This in turn affected the effects of operating conditions on

517 ash behavior that were ranked in the same aforementioned order.

518 The temperature then residence time had higher effects on ash reactivity than cooling and

519 pellet compression rates. $\mathrm{K}_{2} \mathrm{Ca}_{6} \mathrm{Si}_{4} \mathrm{O}_{15}$ and $\mathrm{K}_{2} \mathrm{Ca}_{2} \mathrm{Si}_{2} \mathrm{O}_{7}$ were the main products of the

520 chemical reactions in 50-50 bark-straw biomass and ash mixtures. They were absent in the

521 single feedstock but highly stable at $1000^{\circ} \mathrm{C}$ and $6 \mathrm{~h}$ in the blend in the ash test, conditions at

522 which equilibrium was experimentally reached. Their appearance along with their increasing

523 proportions led to a decrease in the amorphous proportion. Hence, optimizing the blend to

524 increase their concentration has the potential to solve slagging problematic.

525 Laboratory pellet test was able to predict pilot behavior in terms of crystalline and amorphous 526 proportions along with agglomeration distribution for both individual biomasses and biomass

527 mixtures. Hence, using the pellet laboratory test before any pilot operation has the potential to 528 make economic savings and reduce operational problems related to ash behavior in pilot and 529 industrial scale reactors. These results should be checked for other biomass mixtures as well 530 as in the case of FBR where biomass ash may also react with the bed materials. 
[1] Bhaskar T, Pandey A. Advances in Thermochemical Conversion of BiomassIntroduction. Recent Adv. Thermo-Chem. Convers. Biomass, Elsevier; 2015, p. 3-30. https://doi.org/10.1016/B978-0-444-63289-0.00001-6.

[2] Scarlat N, Dallemand J-F, Monforti-Ferrario F, Nita V. The role of biomass and bioenergy in a future bioeconomy: Policies and facts. Environ Dev 2015;15:3-34. https://doi.org/10.1016/j.envdev.2015.03.006.

[3] Vassilev SV, Vassileva CG, Song Y-C, Li W-Y, Feng J. Ash contents and ash-forming elements of biomass and their significance for solid biofuel combustion. Fuel 2017;208:377-409. https://doi.org/10.1016/j.fuel.2017.07.036.

[4] Vassilev SV, Baxter D, Andersen LK, Vassileva CG. An overview of the chemical composition of biomass. Fuel 2010;89:913-33. https://doi.org/10.1016/j.fuel.2009.10.022.

[5] Vassilev SV, Baxter D, Vassileva CG. An overview of the behaviour of biomass during combustion: Part I. Phase-mineral transformations of organic and inorganic matter. Fuel 2013;112:391-449. https://doi.org/10.1016/j.fuel.2013.05.043.

[6] Boström D, Skoglund N, Grimm A, Boman C, Öhman M, Broström M, et al. Ash Transformation Chemistry during Combustion of Biomass. Energy Fuels 2012;26:8593. https://doi.org/10.1021/ef201205b.

[7] Öhman M, Nordin A, Skrifvars B-J, Backman R, Hupa M. Bed Agglomeration Characteristics during Fluidized Bed Combustion of Biomass Fuels. Energy Fuels 2000;14:169-78. https://doi.org/10.1021/ef990107b.

[8] Ma C, Weiland F, Hedman H, Boström D, Backman R, Öhman M. Characterization of Reactor Ash Deposits from Pilot-Scale Pressurized Entrained-Flow Gasification of Woody Biomass. Energy Fuels 2013;27:6801-14. https://doi.org/10.1021/ef401591a.

[9] Froment K, Seiler JM, Poirier J, Colombel L. Determining Cooling Screen Slagging Reactor Operating Temperature. Energy Fuels 2015;29:5069-77. https://doi.org/10.1021/acs.energyfuels.5b00744.

[10] Mack R, Kuptz D, Schön C, Hartmann H. Combustion behavior and slagging tendencies of kaolin additivated agricultural pellets and of wood-straw pellet blends in a small-scale boiler. Biomass Bioenergy 2019;125:50-62. https://doi.org/10.1016/j.biombioe.2019.04.003.

[11] Holubcik M, Jandacka J, Palacka M, Vician P. Additives application to wheat straw to increasing the ash fusion temperature. AIP Conf Proc 2016;1768:020014. https://doi.org/10.1063/1.4963036.

[12] Wang C, Zhao L, Sun R, Hu Y, Tang G, Chen W, et al. Effects of silicon-aluminum additives on ash mineralogy, morphology, and transformation of sodium, calcium, and iron during oxy-fuel combustion of zhundong high-alkali coal. Int J Greenh Gas Control 2019;91:102832. https://doi.org/10.1016/j.ijggc.2019.102832.

[13] Yao X, Zhou H, Xu K, Xu Q, Li L. Evaluation of the fusion and agglomeration properties of ashes from combustion of biomass, coal and their mixtures and the effects of K2CO3 additives. Fuel 2019;255:115829. https://doi.org/10.1016/j.fuel.2019.115829.

[14] Wang L, Hustad JE, Skreiberg Ø, Skjevrak G, Grønli M. A Critical Review on Additives to Reduce Ash Related Operation Problems in Biomass Combustion Applications. Energy Procedia 2012;20:20-9. https://doi.org/10.1016/j.egypro.2012.03.004.

[15] Míguez JL, Porteiro J, Behrendt F, Blanco D, Patiño D, Dieguez-Alonso A. Review of the use of additives to mitigate operational problems associated with the combustion of biomass with high content in ash-forming species. Renew Sustain Energy Rev 2021;141:110502. https://doi.org/10.1016/j.rser.2020.110502. 
[16] Nguyen HK, Moon JH, Jo SH, Park SJ, Bae DH, Seo MW, et al. Ash characteristics of oxy-biomass combustion in a circulating fluidized bed with kaolin addition. Energy 2021;230:120871. https://doi.org/10.1016/j.energy.2021.120871.

[17] Zhou C, Rosén C, Engvall K. Biomass oxygen/steam gasification in a pressurized bubbling fluidized bed: Agglomeration behavior. Appl Energy 2016;172:230-50. https://doi.org/10.1016/j.apenergy.2016.03.106.

[18] Wang Q, Han K, Wang P, Li S, Zhang M. Influence of additive on ash and combustion characteristics during biomass combustion under $\mathrm{O} 2 / \mathrm{CO} 2$ atmosphere. Energy 2020;195:116987. https://doi.org/10.1016/j.energy.2020.116987.

[19] Fournel S, Palacios JH, Godbout S, Heitz M. Effect of Additives and Fuel Blending on Emissions and Ash-Related Problems from Small-Scale Combustion of Reed Canary Grass. Agriculture 2015;5:561-76. https://doi.org/10.3390/agriculture5030561.

[20] Thy P, Jenkins BM, Williams RB, Lesher CE, Bakker RR. Bed agglomeration in fluidized combustor fueled by wood and rice straw blends. Fuel Process Technol 2010;91:1464-85. https://doi.org/10.1016/j.fuproc.2010.05.024.

[21] Zeng T, Pollex A, Weller N, Lenz V, Nelles M. Blended biomass pellets as fuel for small scale combustion appliances: Effect of blending on slag formation in the bottom ash and pre-evaluation options. Fuel 2018;212:108-16. https://doi.org/10.1016/j.fuel.2017.10.036.

[22] Zeng T, Weller N, Pollex A, Lenz V. Blended biomass pellets as fuel for small scale combustion appliances: Influence on gaseous and total particulate matter emissions and applicability of fuel indices. Fuel 2016;184:689-700. https://doi.org/10.1016/j.fuel.2016.07.047.

[23] Thy P, Jenkins BM, Lesher CE, Grundvig S. Compositional constraints on slag formation and potassium volatilization from rice straw blended wood fuel. Fuel Process Technol 2006;87:383-408. https://doi.org/10.1016/j.fuproc.2005.08.015.

[24] Rodríguez JL, Álvarez X, Valero E, Ortiz L, Torre-Rodríguez N de la, Acuña-Alonso C. Design of solid biofuels blends to minimize the risk of sintering in biomass boilers. $\mathrm{J}$ Energy Inst 2020;93:2409-14. https://doi.org/10.1016/j.joei.2020.07.015.

[25] Royo J, Canalís P, Quintana D, Díaz-Ramírez M, Sin A, Rezeau A. Experimental study on the ash behaviour in combustion of pelletized residual agricultural biomass. Fuel 2019;239:991-1000. https://doi.org/10.1016/j.fuel.2018.11.054.

[26] Skrifvars B-J, Öhman M, Nordin A, Hupa M. Predicting bed agglomeration tendencies for biomass fuels fired in FBC boilers: A comparison of three different prediction methods. Energy Fuels 1999;13:359-63. https://doi.org/10.1021/ef980045+.

[27] Defoort F, Campargue M, Ratel G, Miller H, Dupont C. Physicochemical Approach To Blend Biomass. Energy Fuels 2019;33:5820-8. https://doi.org/10.1021/acs.energyfuels.8b04169.

[28] Rebbling A, Sundberg P, Fagerström J, Carlborg M, Tullin C, Boström D, et al. Demonstrating Fuel Design To Reduce Particulate Emissions and Control Slagging in Industrial-Scale Grate Combustion of Woody Biomass. Energy Fuels 2020;34:2574-83. https://doi.org/10.1021/acs.energyfuels.9b03935.

[29] Santoso I, Taskinen P, Jokilaakso A, Paek M-K, Lindberg D. Phase equilibria and liquid phase behavior of the $\mathrm{K} 2 \mathrm{O}-\mathrm{CaO}-\mathrm{SiO} 2$ system for entrained flow biomass gasification. Fuel 2020;265:116894. https://doi.org/10.1016/j.fuel.2019.116894.

[30] Salour D, Jenkins BM, Vafaei M, Kayhanian M. Control of in-bed agglomeration by fuel blending in a pilot scale straw and wood fueled AFBC. Biomass Bioenergy 1993;4:11733. https://doi.org/10.1016/0961-9534(93)90033-Z. 
[31] Nordgren D, Hedman H, Padban N, Boström D, Öhman M. Ash transformations in pulverised fuel co-combustion of straw and woody biomass. Fuel Process Technol 2013;105:52-8. https://doi.org/10.1016/j.fuproc.2011.05.027.

[32] Wang L, Skreiberg Ø, Becidan M. Investigation of additives for preventing ash fouling and sintering during barley straw combustion. Appl Therm Eng 2014;70:1262-9. https://doi.org/10.1016/j.applthermaleng.2014.05.075.

[33] Regueiro A, Patiño D, Granada E, Porteiro J. Experimental study on the fouling behaviour of an underfeed fixed-bed biomass combustor. Appl Therm Eng 2017;112:523-33. https://doi.org/10.1016/j.applthermaleng.2016.10.105.

[34] Royo J, Canalís P, Quintana D. Chemical study of fly ash deposition in combustion of pelletized residual agricultural biomass. Fuel 2020;268:117228. https://doi.org/10.1016/j.fuel.2020.117228.

[35] Link S, Yrjas P, Hupa L. Ash melting behaviour of wheat straw blends with wood and reed. Renew Energy 2018;124:11-20. https://doi.org/10.1016/j.renene.2017.09.050.

[36] Vega-Nieva D, Alvarez C, Ortiz L. Results of new laboratory methods and slagging classification systems for the prediction and quantification of ash slagging in woody and herbaceous biomass fuels. Cent. Eur. Biomass Conf., 2014.

[37] Gilbe C, Lindström E, Backman R, Samuelsson R, Burvall J, Öhman M. Predicting Slagging Tendencies for Biomass Pellets Fired in Residential Appliances: A Comparison of Different Prediction Methods. Energy Fuels 2008;22:3680-6. https://doi.org/10.1021/ef800321h.

[38] Steenari B-M, Lundberg A, Pettersson H, Wilewska-Bien M, Andersson D. Investigation of ash sintering during combustion of agricultural residues and the effect of additives. Energy Fuels 2009;23:5655-62. https://doi.org/10.1021/ef900471u.

[39] Chen M, Hou X, Chen J, Zhao B. Phase Equilibria Studies in the SiO2-K2O-CaO System. Metall Mater Trans B 2016;47:1690-6. https://doi.org/10.1007/s11663-0160623-z. 